\title{
Review of pre end-stage renal disease care in the western region in Saudi Arabia
}

Amal A Hassanien ${ }^{1 *}$, Azeem Majeed ${ }^{1}$, Hilary Watt ${ }^{1}$ and Nawal Basri ${ }^{2}$

*Correspondence: a.hassanien09@imperial.ac.uk

'Department of Primary Care \& Public Health, School of Public Health, Imperial College London, UK.

2Jeddah Kidney Centre, King Fahad General Hospital in Jeddah, Ministry of Health in Saudi Arabia, KSA.

\begin{abstract}
Background: The risk factors for chronic kidney disease (CKD) are increasing in the Saudi population. Consequently, the incidence and prevalence of end-stage renal disease (ESRD) have increased substantially in Saudi Arabia over the past three decades. This study was conducted to review pre-ESRD care and investigate the primary causes of ESRD among haemodialysis patients in the western region in Saudi Arabia.

Methods: A pilot cross-sectional study was conducted in Al-Noor Kidney Centre and Jeddah Kidney Centre in the western region of Saudi Arabia. Participants were patients with ESRD on regular haemodialysis during 2011. Main outcome measures were pre-ESRD care including: reason of referral to nephrology care, source of referral to nephrology care, duration of pre-ESRD care, and vascular access at the first dialysis; and primary causes of ESRD.

Results: Preliminary indicators of pre-ESRD care showed that: endocrine, nutritional and metabolic diseases, and immunity disorders were the principal reason for patient referral in 50.6\% (95\% CIs, 45.1_56.1) of patients; 50.6\% (95\% CIs, 45.6_55.6) of the patient referrals arrived from the emergency department; a large proportion of haemodialysis patients were not receiving pre-ESRD nephrology care, 47.6\% (95\% CIs, 41.7_53.5); the predominant vascular access point for haemodialysis was initially a catheter $88.3 \%$ (95\% CIs, 84.5_91.3). The dominant causes of ESRD were hypertensive nephropathy, 55.8\% (95\% CIs, 50.8_60.7) and diabetic nephropathy, 24.6\% (95\% CIs, 20.4_29.1).

Conclusions: Pre-ESRD nephrology care needs to be improved in Saudi Arabia. Potential strategies could involve: regular screening of high risk people, encouraging communication between healthcare practitioners, and education on the need to refer patients with CKD to nephrology care in earlier disease stages; and increasing patients' awareness about their health conditions and potential consequences of their kidney disease.
\end{abstract}

Keywords: Chronic kidney disease, end-stage renal disease, nephrology care

\section{Background}

End-stage renal disease (ESRD) has emerged as an important public health issue worldwide, because of the marked increase in its incidence and prevalence. This increases the need for multidisciplinary management including financial and social support, and medical care. Early referral of patients with chronic kidney disease (CKD) to specialized renal services can help to preserve renal function and delay the progression of renal failure by preventing and managing the modifiable risk factors of CKD and treating secondary complications [1-3].

Many studies have shown that a long duration of pre-ESRD nephrology care, which is the period between the first time the patient has been seen by a nephrologist and the first dialysis [1], has a significant effect on the quality of life and survival rate in patients with ESRD before and after receiving renal replacement therapy (RRT) $[\mathbf{2 , 4}, \mathbf{5}]$. Improved detection of patients with CKD in its early stages can significantly reduce the prevalence of cardiovascular morbidity, and gives an adequate time to prepare patients for RRT; especially those patients who need to create vascular access for dialysis, as maturation of arterio-venous fistula (AVF) takes from 6 to 8 weeks; and helps to improve pre-emptive renal transplantation treatment $[1,3]$.
National Kidney Foundation- Kidney Disease Outcomes Quality Initiative (NKF-K/DOQI) guidelines recommended that the preparation for RRT should start in CKD stage 4, when the estimated Glomerular Filtration Rate (eGFR) is $<30$ $\mathrm{mls} / \mathrm{min} / 1.73 \mathrm{~m}^{2}[1]$. This gives time to choose and create a suitable dialysis access point, considered a modifiable risk factor for bacteraemia and mortality $[6,7]$, and avoids the need for temporary vascular access. These interventions have a significant impact in improving the quality of life and reducing the financial demands of renal care.

Many reports have shown evidence of increasing prevalence of the most common causes of ESRD in Saudi Arabia such as diabetes [8], and obesity- conditions associated with many chronic diseases [9-11]. Furthermore, the incidence and prevalence of RRT have been increasing substantially in the last three decades [12]. The majority of patients with ESRD are getting their RRT in the form of haemodialysis (around 53.7\%), with $5.1 \%$ on peritoneal dialysis, and with $41.2 \%$ renal graft. Around $70 \%$ of RRT is provided by Ministry of Health free of charge [13].

This study was conducted to review pre-ESRD care and to investigate primary causes of ESRD among haemodialysis 
Hassanien et al. Journal of Diabetes Research and Clinical Metabolism 2013,

patients in the western region of Saudi Arabia. Pre-ESRD nephrology care was reviewed by describing the preliminary indicators including: the reason of referral to nephrology care, referral source to nephrology care, pre-ESRD care period, and access type at the first dialysis. The results of this study may be valuable for public health planners and healthcare professionals in Saudi Arabia to prepare a strategy to define and screen people at high risk and improve rates of early referral to nephrology care, both which rely upon multidisciplinary demands.

\section{Methods}

\section{Study design and setting}

A cross-sectional study was conducted in two large haemodialysis centers in the western region of Saudi Arabia: Alnoor Kidney Centre (AKC) in AI Noor Specialist Hospital in Makkah city and Jeddah Kidney Centre (JKC) in King Fahad General Hospital in Jeddah city. Both are Ministry of Health Hospitals, and therefore are expected to have similar quality of healthcare services. Data was obtained after applying for ethical approval from the Ministry of Health \& General Directorate of Health Affairs in each city.

\section{Study population}

Participants were the prevalent patients with ESRD on regular haemodialysis during 2011. This haemodialysis population was chosen for two reasons: according to Saudi Centre for Organ Transplantation report, they constitute the largest population among patients with RRT in Saudi Arabia [14]. these patients are easy to find, extract their medical history, and follow-up retrospectively from medical records in dialysis centers despite the lack of primary care networks and health information systems. All visiting patients to dialysis centers, who do not have a documented medical history in medical records, and patients with advanced malignancy were excluded.

\section{Data collection}

Electronic medical records were searched to identify all patients with ESRD on haemodialysis in 2011. The total number of patients on haemodialysis in Al-Noor Specialist Hospital in Makkah was 418, and King Fahad General Hospital in Jeddah was 634. A simple random sampling technique was used to select a sample of 69 patients from JKC because of time limitations; all patients from AKC were included except 84 visiting patients to the dialysis centre without a medical history who were excluded. The requested data including demographic information, date first seen by nephrologist, reason of referral to nephrologist, referral source to nephrology care, date of first dialysis, access type at first dialysis, and causes of ESRD were collected from medical records and stored in a customized Microsoft Office Access database.

\section{Statistical analysis}

Patient's age at referral time to nephrology care and the pre-ESRD care period were calculated. Pre-ESRD care period was categorized as following: 0 months, $<6$ months, $6-12$ months, and $>12$ months. Reasons of referral to nephrologists were classified using ICD-9-CM: disease of the genitourinary system including disorders of urethra and urinary tract such as haematuria; disease of the circulatory system including uncontrolled blood pressure; endocrine, nutritional and metabolic diseases and, immunity disorders including diabetic nephropathy, nephrolithiasis, disorders of fluid electrolyte such as hyperkalaemia and hyperphosphatemia, and unspecified disorders of metabolism; symptoms and signs indicate to renal diseases including proteinuria, abnormal creatinine clearance, and eGFR <30; and not reported. Also, primary causes of ESRD were classified according to ICD-9-CM to the following categories: diabetes, glomerulonephritis (GN), secondary GN/vasculitis, interstitial nephritis/pyelonephritis, hypertension/large vessel disease, cystic/hereditary/congenital diseases, neoplasms/tumors, and miscellaneous conditions.

Data were analyzed descriptively to describe the preliminary indicators of pre-ESRD care and investigate the primary causes of ESRD. To examine uncertainty, the $95 \%$ confidence intervals (Cls) were calculated for each outcome. Additional analyses were also performed. T-test for two independent means was performed to examine the associations between age at referral time to nephrology care and sex. Chi-square or Fisher exact test was performed to examine the relation between the pre-ESRD care period with age, sex, referral source, the reason of referral to nephrology care, dominant causes of ESRD, and AVF as vascular access at first haemodialysis. Logistic regression was performed to examine the association between AVF as vascular access at first haemodialysis with age, sex, referral source, the reason of referral to nephrology care, period of pre-ESRD, and dominant causes of ESRD as predictors. All the analyses were performed using STATA 11.

\section{Results}

\section{Patients' characteristics}

The total sample size was 403 haemodialysis patients, derived from two dialysis centers: 334 from AKC and 69 from JKC (Figure 1). 93.1\% of the study population were Saudis. Males constituted $57.3 \%$ of the study population. The mean age at referral time to nephrology care was 44.3 (standard deviation $(\mathrm{SD})= \pm 16.4$ ). T-test shows that there was no significant difference between the mean age for males (43.6) and females (45.4) at referral time to nephrology care with a mean difference of $(1.8 ; 95 \% \mathrm{Cls},-2.01$ to 5.8 ; $\mathrm{p}=0.18$ ). The mean of period of haemodialysis was 6.2 years $(\mathrm{SD}= \pm 5.2) .27$ patients of the study sample died, and $10 \mathrm{had}$ renal transplantation during 2011 in AKC (Table 1).

\section{Preliminary indicators of pre-ESRD care and primary causes of ESRD}

In the study sample, the most commonly reported reasons for referral to nephrology care are endocrine, nutritional and metabolic diseases, $50.6 \%$, followed by disease of circulatory system, $39.9 \%$, symptoms and signs indicate to renal function 


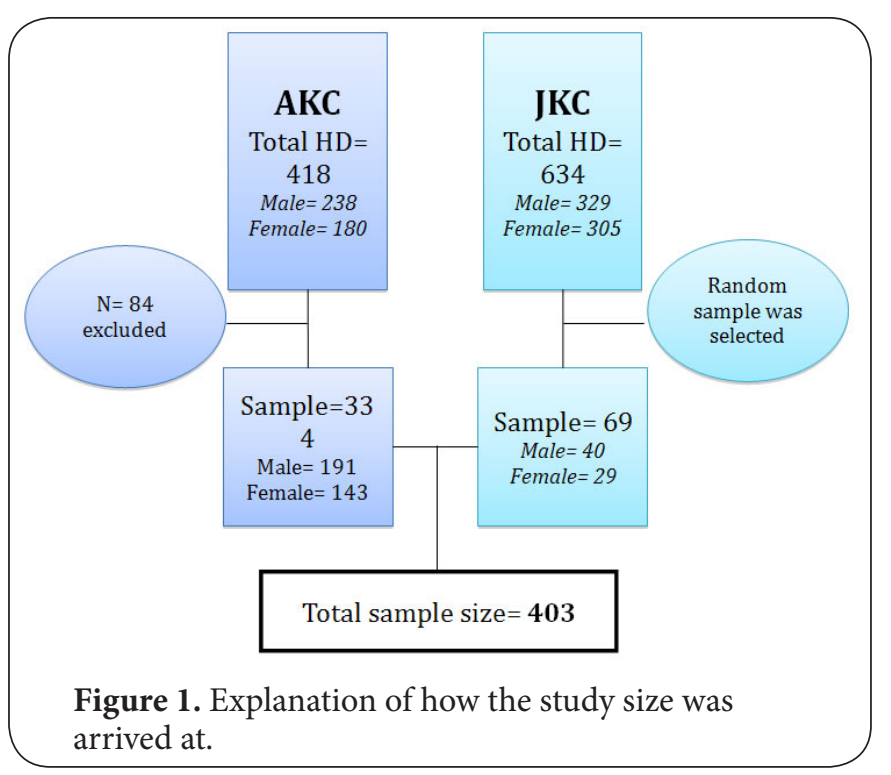

Table 1. Summary of Patients characteristics.

\begin{tabular}{lc}
\hline Patient characteristics & Outcome \\
\hline Patients' source & 334 \\
Alnoor Kidney Centre & 69 \\
Jeddah Kidney Centre & \\
Age at referral to nephrology care & $44.3(16.4)$ \\
Mean(SD) & $(1.9,89.7)$ \\
Range(low, high) & 113 \\
Missing & \\
Sex (\%) & $231(57.3)$ \\
Male & \\
Nationality (\%) & $375(93.1)$ \\
Saudi & \\
Period of dialysis in years & $6.2(5.2)$ \\
Mean(SD) & $(0.01,21.2)$ \\
Range(low, high) & 13 \\
Missing & \\
Patient status during 2011 & 366 \\
Survive & 27 \\
Dead & 10 \\
Renal transplanted &
\end{tabular}

$\mathrm{SD}=$ standard deviation.

deterioration, $6 \%$, diseases of genitourinary system, $3.6 \%$; in 67 records, reasons for referral were missing or not reported. Referral from the emergency departments for urgent dialysis served as the principal referral source for $50.6 \%$; other sources included from out-patient clinics for renal care, $27.8 \%$, and from different healthcare centers for dialysis, $21.6 \%$. The preESRD care period ranged between 0-274 months with 113 missing records. $47.6 \%$ of haemodialysis patients had not

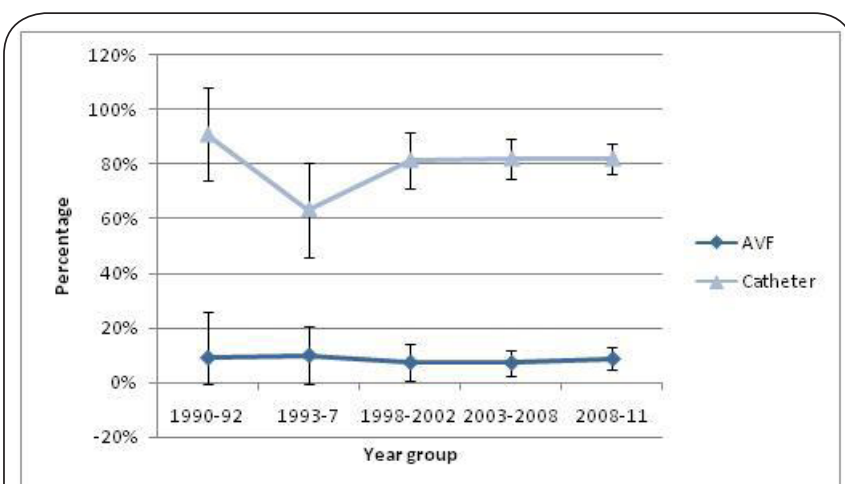

Figure 2. Vascular access at first dialysis in recent decade. $\mathrm{AVF}=$ Arterio-venous fistula.

received pre-ESRD nephrology care, $28.6 \%$ of patients had received care for $<6$ months, $6.9 \%$ received care between 6-12 months, and $16.9 \%$ received care for $>12$ months. The principal access point for dialysis in the study sample was via a catheter at $88.3 \% .8 .9 \%$ were initiated through an AVF, 2.5\% initiated with an arterio-venous graft and $0.3 \%$ were initiated with peritoneal dialysis. To avoid misinterpretation, the trend for AVF and catheter as vascular access at first dialysis was examined (Figure 2). There has been no improvement in referring patients to create AVF before first dialysis during the last decade, while the number of patients who started dialysis with catheter has not decreased. The dominant cause of ESRD is hypertension/large vessel disease, $55.8 \%$ followed by diabetes, $24.6 \%$, cystic/hereditary/congenital disease, $7.2 \%$, GN 6.5\%, interstitial nephritis or pyelonephritis, $4.5 \%$, secondary GN/vasculitis, $1 \%$, and $0.5 \%$ unknown (Table 2).

\section{Comparisons}

There was no significant statistical relation between preESRD care period with age $(p=0.06)$, sex $(p=0.6)$, diabetic nephropathy $(p=0.6)$ and hypertensive nephropathy $(p=0.97)$ as primary causes of ESRD. The relation between pre-ESRD care period and reason of referral to nephrology care was statistically significant $(p=0.005)$, where the majority of patients within all reasons of referral had not received preESRD nephrology care or they had received care but for less than six months. There was a significant association between pre-ESRD care period and referral sources $(p=<0.0001)$, where patients with CKD who had not received pre-ESRD care were more likely to be referred from emergency departments. Consequently, there is a strong relation between preESRD care periods and initiating haemodialysis with AVF $(p=<0.0001)$ (Table 3).

The relationship between initiating haemodialysis with AVF with age, and sex were not statistically significant. However, it seems there is a proportional relationship between pre-ESRD care period and initiating haemodialysis with AVF. Patients who had received care for between 6-12 months were less likely by $60 \%$ to initiate haemodialysis with AVF (OR $=0.4$, 
Table 2. Preliminary indicators of pre-ESRD care and primary causes of ESRD

\begin{tabular}{|c|c|c|}
\hline Outcome & Frequency & $\%(95 \%$ CIs $)$ \\
\hline \multicolumn{3}{|l|}{ Reason of referral to nephrologist } \\
\hline Diseases of genitourinary system & 12 & 3.6(1.9_6.2) \\
\hline Disease of circulatory system & 134 & 39.9(34.6_45.3) \\
\hline $\begin{array}{l}\text { Endocrine, nutritional and metabolic } \\
\text { diseases \& immunity disorders }\end{array}$ & 170 & 50.6(45.1_56.1) \\
\hline $\begin{array}{l}\text { Symptoms and signs indicate to renal } \\
\text { diseases }\end{array}$ & 20 & 6(3.7_9.0) \\
\hline Missing/Not reported & 67 & - \\
\hline \multicolumn{3}{|l|}{ Referral source } \\
\hline Emergency & 204 & 50.6(45.6_55.6) \\
\hline Outpatient clinic & 112 & $27.8\left(23.5 \_32.4\right)$ \\
\hline Other healthcare centres & 87 & 21.6(17.7_25.9) \\
\hline \multicolumn{3}{|l|}{ Period of pre-ESRD care/month } \\
\hline 0 months (Not receiving pre-ESRD care) & 138 & 47.6(41.7_53.5) \\
\hline$<6$ months & 83 & 28.6(23.5_34.2) \\
\hline 6-12 months & 20 & $6.9\left(4.3 \_10.5\right)$ \\
\hline$>12$ months & 49 & $16.9\left(12.8 \_21.7\right)$ \\
\hline Missing/Not reported & 113 & - \\
\hline \multicolumn{3}{|l|}{ Access at first dialysis } \\
\hline AVF & 32 & 8.9(6.2_12.4) \\
\hline AVG & 9 & $2.5\left(1.2 \_4.7\right)$ \\
\hline Catheter & 317 & 88.3(84.5_91.3) \\
\hline $\mathrm{PD}$ & 1 & $0.3\left(0 \_1.5\right)$ \\
\hline Missing/Not reported & 44 & - \\
\hline \multicolumn{3}{|l|}{ Primary causes of ESRD } \\
\hline Cystic/Hereditary/Congenital disease & 29 & 7.2(4.9_10.2) \\
\hline Diabetes & 99 & 24.6(20.4_29.1) \\
\hline Glomerulonephritis & 26 & 6.5(4.3_9.3) \\
\hline Hypertension/Large vessel disease & 225 & $55.8\left(50.8 \_60.7\right)$ \\
\hline Interstitial nephritis/Pyelonephritis & 18 & $4.5\left(2.7 \_7\right)$ \\
\hline Secondary GN/Vasculitis & 4 & $1\left(0.3 \_2.5\right)$ \\
\hline Miscellaneous conditions & 2 & $0.5\left(0.1 \_1.8\right)$ \\
\hline
\end{tabular}

$\mathrm{AVF}=$ arterio-venous fistula, $\mathrm{AVG}=$ arterio-venous graft, $\mathrm{PD}=$ peritoneal dialysis.

$95 \% \mathrm{Cls}, 0.1$ to $1.7 ; \mathrm{p}=0.2$ ) but there was insufficient evidence for this association, while patients who had received care for $<6$ months were less likely by $70 \%$ to initiate haemodialysis with AVF (OR=0.3; 95\% Cls, 0.14 to $0.9 ; p=0.02$ ) compared to patients who had received care $>12$ months. Thus, patients who were referred from other different healthcare centers for renal care were two times more likely to initiate haemodialysis with AVF but this association is not statistically significant $(\mathrm{OR}=2,95 \% \mathrm{Cls}, 0.6$ to $6.6 ; \mathrm{p}=0.2)$, and patients who were referred from outpatients clinics were six times more likely to initiate haemodialysis with AVF (OR=6.3; $95 \% \mathrm{Cls}, 2.7$ to $15.5 ; p=<0.0001$ ) compared to patients who were referred from emergency departments. Also, there is a significant association between the reason of referral to nephrology care and initiating haemodialysis with AVF in the study sample. The patients who were referred to nephrology care because of circulatory system diseases were less likely by $80 \%(\mathrm{OR}=0.2$; $95 \% \mathrm{Cls}, 0.04$ to $0.6 ; \mathrm{p}=0.005)$; and endocrine, nutritional and metabolic diseases were less likely by $9 \%(\mathrm{OR}=0.07$; $95 \% \mathrm{Cls}, 0.02$ to $0.3 ; \mathrm{p}=<0.0001$ ) to initiate haemodialysis with AVF compared to patients who were referred because of genitourinary system diseases. Patients with diabetic nephropathy were $46 \%$ less likely to initiate haemodialysis with AVF compared to non-diabetic patients $(\mathrm{OR}=0.54$; $95 \% \mathrm{Cls}, 0.2$ to $1.4 ; \mathrm{p}=0.2$ ); also, patients with hypertensive nephropathy were $62 \%$ more likely to initiate haemodialysis with AVF compared to non-hypertensive patients $(\mathrm{OR}=1.62$; $95 \% \mathrm{Cls}, 0.77$ to $3.5 ; \mathrm{p}=0.2)$; however, these relationships were not statistically significant (Table 4).

\section{Discussion}

In Saudi Arabia, the risk factors for CKD have risen in recent decades with a corresponding rise in the incidence and prevalence of RRT. We reviewed pre-ESRD care and the primary causes of ESRD to provide evidence of the quality of renal care services before starting dialysis.

The indicators of pre-ESRD nephrology care show that; around $41.7-53.5 \%$ of haemodialysis patients had not received renal care at all before initiating dialysis, and around 23.5$34.2 \%$ had received care but for less than six months. This means there is a reduced chance for patients to take part in clinical decisions regarding RRT options. Also, it means inadequate time to provide a pre-dialysis educational program and psychological preparation for patients with CKD, and inadequate time to create a suitable point for permanent vascular access to be used at first dialysis.

This resulted in around $45.6-55.6 \%$ of patients with ESRD being referred from emergency departments for urgent haemodialysis. This in turn led to around $84.5-91.3 \%$ of patients with ESRD to have initiated haemodialysis with a catheter, which is associated with increased risk of hospitalization and mortality $[7,15,16]$. The K/DOQI guidelines for vascular access in haemodialysis recommended that $65 \%$ of all incident haemodialysis patients should start dialysis with AVF [17], which is associated with reducing access complications and improving patients' survival [16]. In the study population, only around $6.2-12.4 \%$ of patients have initiated haemodialysis with AVF. Furthermore, the trend of incidence of haemodialysis patients with AVF has not showed any improvement in recent decade.

NKF-K/DOQI guidelines states that, adverse outcomes of CKD such as loss of kidney function, kidney failure, and cardiovascular disease, can be prevented or delayed by detecting and treating CKD at earlier stages. This can be done 
Table 3. Relation between pre-ESRD care periods and patient characteristics.

\begin{tabular}{|c|c|c|c|c|c|c|}
\hline \multirow[t]{2}{*}{ Outcome } & \multicolumn{4}{|c|}{ Pre-ESRD care period } & \multirow[t]{2}{*}{ Total $(\%)$} & \multirow[t]{2}{*}{ p-value } \\
\hline & $>12 \mathrm{~m}$ & 6-12m & $<6 \mathrm{~m}$ & 0m & & \\
\hline \multicolumn{7}{|l|}{ Age at referral time to nephrology care } \\
\hline$<14.9$ & 5 & 0 & 1 & 2 & $8(2.8)$ & \\
\hline $15-29.9$ & 11 & 3 & 16 & 24 & $54(18.6)$ & \\
\hline $30-44.9$ & 14 & 5 & 21 & 43 & $83(28.6)$ & \\
\hline $45-59.9$ & 15 & 5 & 28 & 46 & $94(32.4)$ & \\
\hline$\geq 60$ & 4 & 7 & 17 & 23 & $51(17.6)$ & 0.06 \\
\hline \multicolumn{7}{|l|}{ Sex } \\
\hline female & 20 & 8 & 27 & 57 & $112(38.6)$ & \\
\hline male & 29 & 12 & 56 & 81 & $178(61.4)$ & 0.6 \\
\hline \multicolumn{7}{|l|}{ Referral source } \\
\hline Emergency department & 7 & 6 & 36 & 108 & $157(54.1)$ & \\
\hline Other healthcare centres & 11 & 5 & 11 & 17 & $44(15.2)$ & \\
\hline Outpatient clinic & 31 & 9 & 36 & 13 & $89(30.7)$ & $<0.0001$ \\
\hline \multicolumn{7}{|l|}{ Reason of referral to nephrologist } \\
\hline Diseases of genitourinary system & 4 & 4 & 2 & 1 & $11(4.4)$ & \\
\hline Disease of circulatory system & 12 & 4 & 31 & 39 & $86(34.1)$ & \\
\hline $\begin{array}{l}\text { Endocrine, nutritional and metabolic diseases \& } \\
\text { immunity disorders }\end{array}$ & 19 & 11 & 41 & 69 & $140(55.6)$ & \\
\hline Symptoms and signs indicate to renal diseases & 2 & 0 & 4 & 9 & $15(6)$ & 0.005 \\
\hline \multicolumn{7}{|l|}{ Diabetic nephropathy } \\
\hline No & 36 & 13 & 60 & 107 & $216(74.5)$ & \\
\hline Yes & 13 & 7 & 23 & 31 & $74(25.5)$ & 0.6 \\
\hline \multicolumn{7}{|l|}{ Hypertensive nephropathy } \\
\hline No & 24 & 9 & 37 & 64 & $134(46.2)$ & \\
\hline Yes & 25 & 11 & 46 & 74 & $156(53.8)$ & 0.97 \\
\hline \multicolumn{7}{|l|}{ Starting HD with AVF } \\
\hline No & 35 & 17 & 73 & 138 & $263(90.7)$ & \\
\hline Yes & 14 & 3 & 10 & 0 & $27(9.3)$ & $<0.0001$ \\
\hline
\end{tabular}

$\mathrm{HD}=$ haemodialysis, $\mathrm{AVF}=$ arterio-venous fistula.

through routine laboratory measurements and eGFR. However, declining eGFR is associated with multiple complications such as hypertension, anaemia, malnutrition, neuropathy, and bone disease. All these complications can be treated at earlier stages of CKD [2]. In this study, many of the patients around $45.1-56.1 \%$ were referred to nephrology care because of endocrine, nutritional, and metabolic diseases; and 34.6$45.3 \%$ were referred because of uncontrolled blood pressure. The majority of those patients had not received nephrology care or the period of care was less than six months, while the dominant causes of ESRD were hypertensive nephropathy (50.8-60.7\%) and diabetic nephropathy (20.4-29.1\%).

This study shows that there is a significant association between the pre-ESRD care period and reasons of referral to nephrology care. The majority of patients with CKD had not received pre-ESRD care or they received less than six months of care in all reasons of referral; most patients with ESRD were referred from emergency for urgent haemodialysis. A similar study that was conducted at Jeddah Kidney Centre in 2002, which used serum creatinine as an indicator of late referral, showed that the mean serum creatinine when first seen by a nephrologist was high, around $300 \mathrm{mmol} / \mathrm{l}$ [18]. Another screening study for CKD was conducted in Riyadh in Saudi Arabia using eGFR and laboratory measurements to detect CKD in the general population. This showed that around 7\% of patients with CKD were not aware about their kidney status, $32 \%$ had known they had protein or blood in urine, and $11 \%$ had known they had kidney stones; for the last two, it was not mentioned whether they were followed up by nephrology care services [19]. These reflect delayed referral to nephrology 
Table 4. Relation between initiating haemodialysis with AVF as outcome and different patient characteristics.

\begin{tabular}{|c|c|c|c|c|}
\hline \multirow[t]{2}{*}{ Predictor } & \multicolumn{2}{|c|}{ Starting HD with AVF } & \multirow{2}{*}{$\begin{array}{c}\text { Odds ratio } \\
(95 \% \text { CIs })\end{array}$} & \multirow[t]{2}{*}{ p-value } \\
\hline & No & Yes & & \\
\hline \multicolumn{5}{|l|}{ Age at referral time to nephrology care } \\
\hline$<14.9$ & 6 & 2 & 1 & - \\
\hline $15-29.9$ & 48 & 6 & $0.4\left(0.06 \_2.3\right)$ & 0.3 \\
\hline $30-44.9$ & 77 & 6 & $0.2\left(0.04 \_1.4\right)$ & 0.1 \\
\hline 45-59.9 & 84 & 10 & $0.4\left(0.06 \_2\right)$ & 0.2 \\
\hline$\geq 60$ & 48 & 3 & $0.2\left(0.03 \_1.4\right)$ & 0.1 \\
\hline \multicolumn{5}{|l|}{ Sex } \\
\hline Female & 135 & 12 & 1 & - \\
\hline Male & 192 & 20 & $1.2\left(0.56 \_2.5\right)$ & 0.6 \\
\hline \multicolumn{5}{|l|}{ Referral source } \\
\hline Emergency department & 181 & 7 & 1 & - \\
\hline Other healthcare centres & 64 & 5 & $2\left(0.6 \_6.6\right)$ & 0.2 \\
\hline Outpatient clinic & 82 & 20 & 6.3(2.7_15.5) & $<0.0001$ \\
\hline \multicolumn{5}{|l|}{ Period of pre-ESRD care/month } \\
\hline$>12$ month & 35 & 14 & 1 & - \\
\hline $6-12$ month & 17 & 3 & $0.4\left(0.1 \_1.7\right)$ & 0.2 \\
\hline$<6$ month & 73 & 10 & $0.3\left(0.14 \_0.85\right)$ & 0.02 \\
\hline 0month & 138 & 0 & - & - \\
\hline \multicolumn{5}{|l|}{ Reason of referral to nephrologist } \\
\hline Diseases of genitourinary system & 6 & 5 & 1 & - \\
\hline Disease of circulatory system & 102 & 13 & $0.2\left(0.04 \_0.6\right)$ & 0.005 \\
\hline Endocrine, nutritional and metabolic diseases \& immunity disorders & 152 & 9 & $0.07\left(0.02 \_0.3\right)$ & $<0.0001$ \\
\hline Symptoms and signs indicate to renal diseases & 15 & 2 & $0.2\left(0.02 \_1.1\right)$ & 0.06 \\
\hline \multicolumn{5}{|l|}{ Diabetic nephropathy } \\
\hline No & 243 & 27 & 1 & - \\
\hline Yes & 84 & 5 & $0.54\left(0.2 \_1.4\right)$ & 0.2 \\
\hline \multicolumn{5}{|l|}{ Hypertensive nephropathy } \\
\hline No & 150 & 11 & 1 & - \\
\hline Yes & 177 & 21 & 1.62(0.77_3.5) & 0.2 \\
\hline
\end{tabular}

$\mathrm{HD}=$ haemodialysis, $\mathrm{AVF}=$ arterio-venous fistula.

care from other services such as primary care, diabetology, and cardiology. Also, where strong primary healthcare and health information systems are absent, it might reflect that there are many patients with CKD and its risk factors such as diabetes, hypertension, and cardiovascular disease undiagnosed in the general population or who were diagnosed but were not followed up consistently, which maybe why the majority of them were not referred to nephrology care in the early stages of their disease.

Due to time limitations for collecting data, a lack of national health information system in Saudi Arabia and some patients being referred from one healthcare centre to another, the laboratory measurements for renal function deterioration and eGFR were not usually available at referral time to nephrology care in many medical records and even the reason of referral was often insufficiently explained. Furthermore, eGFR could not be calculated to determine at which CKD stage the patient had been referred to nephrology care due to missing or not reported information. The Modification of Diet in Renal Disease (MDRD) study equation to estimate GFR require taking into account serum creatinine concentration, age, sex, race, and body mass index [2]. Therefore, the preliminary indicators for pre-ESRD nephrology care were used in this study for detecting late referral to nephrology care. There is a potential selection bias in terms of the study population due to focusing on haemodialysis patients only. Patients with ESRD who initiate RRT with peritoneal dialysis or had preemptive renal transplanted; they would have been referred 
to nephrology care at early stage.

\section{Conclusion}

This study provides information on the status of pre-ESRD care in Saudi Arabia and suggests that pre-ESRD care must be improved. This can be done through developing multidisciplinary strategies including; first, define patients at high risk and conduct regular screening to detect CKD in its early stages. Second, nephrology departments in healthcare centres should organise campaigns to educate healthcare practitioners including family physicians, diabetologists, cardiologists and internists about the necessity of referral patients with CKD to nephrology care at earlier stages of their illness. Third, improve communication channels between healthcare practitioners, and defining accurate criteria as to when to refer patients with CKD to nephrology care using a standardised tools [3]. Fourth, healthcare practitioners and social workers should organise programs to increase patients' awareness about their health status and potential complications. Fifth, patients at high risk of ESRD should be educated about their CKD and trained to better self-manage. As a part of a preventative strategy of chronic diseases, health information system must be developed in Saudi Arabia to evaluate population health and the quality of healthcare services consistently.

\section{Competing interests}

The authors declare that they have no competing interests.

\section{Authors' contributions}

AH designed study, created electronic database for data collection, collected data, performed statistical analyses, and drafted the manuscript. AM contributed in study design, coordination of the study, and reviewed the manuscript critically. HW contributed in statistical analyses, interpretation of data, and reviewed the manuscript critically. NB reviewed the manuscript critically.

\section{Acknowledgement}

Amal Hassanien is funded by a scholarship from Ministry of Higher Education in Saudi Arabia. Thanks to JKC, AKC, and medical records department in Al-Noor hospital for their help and host during data collection. Also, thanks to Mr. Farzan Ramzan for his help in creating database, Mrs. Elizabeth Cecil for her help in data management, and Dr. Noora Al-Kubaisi for her help in coding the reason of referral to nephrology care. The Department of Primary Care \& Public Health at Imperial College London is grateful for support from the North-West London NIHR Collaboration for Leadership in Applied Health Research \& Care, the Imperial NIHR Biomedical Research Centre, and the Imperial Centre for Patient Safety and Service Quality.

Publication history

Received: 05-Dec-2012 Revised: 13-Jan-2013

Accepted: 01-Mar-2013 Published: 07-Mar-2013

\section{References}

1. Sijpkens YWJ, Berkhout-Byrne NC, Rabelink TJ: Optimal predialysis care. Nephrol Dial Transplant Plus 2008, 1:7-13. | Article

2. Levey AS, Coresh J, Balk E, Kausz AT, Levin A, Steffes MW, Hogg RJ, Perrone RD, Lau J and Eknoyan G: National Kidney Foundation practice guidelines for chronic kidney disease: evaluation, classification and stratification. Ann Intern Med 2003, 139:137-47. | Pdf | PubMed

3. Baer G, Lameire N, Van Biesen W: Late referral of patients with end stage renal disease: an in depth review and suggestions for further actions. NDT Plus 2010, 3:17-27. | Article

4. Levin A: Consequences of late referral on patient outcomes. Nephrol Dial Transplant 2000, 15 Suppl 3:8-13. | Article | PubMed

5. Sesso $R$ and Belasco AG: Late diagnosis of chronic renal failure and mortality on maintenance dialysis. Nephrol Dial Transplant 1996, 11:2417-20. | Article | PubMed

6. Thomson PC, Stirling CM, Geddes CC, Morris ST and Mactier RA: Vascular access in haemodialysis patients: a modifiable risk factor for bacteraemia and death. QJM 2007, 100:415-22. | Article | PubMed

7. Pisoni RL, Arrington CJ, Albert JM, Ethier J, Kimata N, Krishnan M, Rayner HC, Saito A, Sands JJ, Saran R, Gillespie B, Wolfe RA and Port FK: Facility hemodialysis vascular access use and mortality in countries participating in DOPPS: an instrumental variable analysis. Am J Kidney Dis 2009, 53:475-91. | Article | PubMed

8. Farag YM and Gaballa MR: Diabesity: an overview of a rising epidemic. Nephrol Dial Transplant 2011, 26:28-35. | Article | PubMed

9. Ng SW, Zaghloul S, Ali HI, Harrison G and Popkin BM: The prevalence and trends of overweight, obesity and nutrition-related non-communicable diseases in the Arabian Gulf States. Obes Rev 2011, 12:1-13. | Article | PubMed

10. Al-Nozha MM, Al-Mazrou YY, Al-Maatouq MA, Arafah MR, Khalil MZ, Khan NB, Al-Marzouki K, Abdullah MA, Al-Khadra AH, Al-Harthi SS, Al-Shahid MS, Al-Mobeireek A and Nouh MS: Obesity in Saudi Arabia. Saudi Med J 2005, 26:824-9. | Article | PubMed

11. Mabry RM, Reeves MM, Eakin EG and Owen N: Evidence of physical activity participation among men and women in the countries of the Gulf cooperation council: a review. Obes Rev 2010, 11:457-64. | Article I PubMed

12. Hassanien AA, Al-Shaikh F, Vamos EP, Yadegarfar G and Majeed A: Epidemiology of end-stage renal disease in the countries of the Gulf Cooperation Council: a systematic review. JRSM Short Rep 2012, 3:38. I Article | PubMed Abstract | PubMed Full Text

13. Al-Sayyari AA and Shaheen FA: End stage chronic kidney disease in Saudi Arabia. A rapidly changing scene. Saudi Med J 2011, 32:339-46. I Pdf I PubMed

14. Saudi Centre for Organ Transplantation. Annual Report 2011. I Website

15. Bray BD, Boyd J, Daly C, Donaldson K, Doyle A, Fox JG, Innes A, Khan I, Peel RK, Severn A, Shilliday I, Simpson K, Stewart GA, Traynor J and Metcalfe W: Vascular access type and risk of mortality in a national prospective cohort of haemodialysis patients. QJM 2012, 105:1097-103. | Article | PubMed

16. Astor BC, Eustace JA, Powe NR, Klag MJ, Fink NE and Coresh J: Type of vascular access and survival among incident hemodialysis patients: the Choices for Healthy Outcomes in Caring for ESRD (CHOICE) Study. J Am Soc Nephrol 2005, 16:1449-55. | Article | PubMed

17. III. NKF-K/DOQI Clinical Practice Guidelines for Vascular Access: update 2000. Am J Kidney Dis 2001, 37:S137-81. | PubMed

18. Shaheen FA and Basri NA: Pre-end stage chronic renal failure: the jeddah kidney center experience. Saudi I Kidney Dis Transp/ 2002, 13:371-5. | Article | PubMed

19. Alsuwaida AO, Farag YM, Al Sayyari AA, Mousa D, Alhejaili F, Al-Harbi A, Housawi A, Mittal BV and Singh AK: Epidemiology of chronic kidney disease in the Kingdom of Saudi Arabia (SEEK-Saudi investigators) - a pilot study. Saudi J Kidney Dis Transp/ 2010, 21:1066-72. | Article | PubMed

\section{Citation:}

Hassanien A A, Majeed A, Watt $\mathrm{H}$ and Basri N: Review of pre end-stage renal disease care in the western region in Saudi Arabia. Journal of Diabetes Research and Clinical Metabolism 2013, 2:12.

http://dx.doi.org/10.7243/2050-0866-2-12 